Document ID \#P109453

\title{
FY 2007 Progress Report For Upper Columbia United Tribes' Regional Coordination
}

Project Number: 2007-108-00

Contract No. 00033650

Reporting Period FY 2007

4/01/07 - 11/30/08

Prepared By:

\author{
DR Michel \\ Executive Director \\ Upper Columbia United Tribes \\ 25 W Main, Suite 434 \\ Spokane, WA 99201
}




\section{Introduction:}

This report is a summary of activities conducted over the fiscal year 2007 contract period to fulfill requirements to coordinate Upper Columbia United Tribes (UCUT) interests within the Columbia River Basin. This coordination was specific to the implementation of portions of the Integrated Fish and Wildlife Program within the purview of the Northwest Power and Conservation Council and Bonneville Power Administration.

\section{Summary of Activities:}

A) Participation in regional Fish and Wildlife Program-related activities:

The UCUT participated in many regularly-scheduled and ad hoc meetings relating to water, fish, wildlife and other natural and cultural resources of the Columbia River Basin, including meetings with the Columbia Basin Fish \& Wildlife Authority (CBFWA), Bonneville Power Administration (BPA) and the Northwest Power \& Conservation Council (NPCC). The UCUT staff tracked and reported back to the member Tribes on issues of interest to them. Developed and conveyed Tribes' positions on issues as their representative in meetings.

Wildlife issues were focused in two areas: the wildlife O\&M review by the IEAB and Program amendment recommendations.

Resident Fish issues were focused in two areas: non-native fish review by the ISAB and Program amendment recommendations.

B) Collaborate and report on evolving definition of Regional Coordination:

UCUT staff participated in meetings to discuss, describe and define regional coordination. In February of 2008, the definition had broad support and concurrence from Fish and Wildlife Managers in the Basin. However, these meetings were unable to make specific funding recommendations to the NPCC and BPA as there were two points of view. One had the UCUT technical staff making a funding recommendation consistent with the definitions that dispersed funding equally to each fish and wildlife manager, allowing them to make explicit decisions regarding how each entities funding was to be used. The other point of view was that the region's Fish and Wildlife Managers required needs based budgeting that exceeded NPCC and BPA agreed upon limits. The UCUT has submitted a request to BPA to enter into government-to-government negotiations to reach a more equitable solution to the NPCC recommendation. Our future direction is to support the regional coordination definition as agreed upon through this process. We will submit it as a Program amendment recommendation along with a 
dispersed funding model that will allow each of the UCUT member Tribes to receive an equal portion of the coordination funding, through which each member Tribe will make explicit decisions about how and what it is spent for and through whom (membership organizations). This approach will support sovereignty as well as allow for fully functioning membership organizations and systems that support all members.

C) Facilitate consensus-based coordination:

Organized and conducted regular monthly meetings of the UCUT technical, management, and policy representatives. In addition to organizing and conducting regular and special meetings, the UCUT staff also assisted with the dissemination of both Technical and Policy information within the UCUT on a broad range of issues that assisted in consensus-based coordination. Also compiled many draft documents for member Tribes review and discussion. Organized presentations on behalf of UCUT, and maintained frequent phone/personal contacts with member Tribes. Established and continued communications between the UCUT, and numerous other agencies, including: management officials of BPA, CBFWA, and representatives of the NPCC.

D) Manage BPA Contract and any subcontracts under it:

The UCUT worked with member Tribes technical staff, and BPA staff to insure compliance with coordination contract. There were no subcontracts established under this contract. 